\title{
UNIVERSITY STUDENTS' GROWTH GOALS, OPPORTUNITIES FOR GOAL FULFILLMENT, AND PERCEIVED UNIVERSITY AND MESOSYSTEM SUPPORT
}

\author{
Zigmunds Freibergs \\ University of Latvia, Latvia \\ Aleksandrs Kolesovs \\ University of Latvia, Latvia
}

\begin{abstract}
This study assessed the relationship between students' growth goals and perceived opportunities to achieve these goals in Latvia and the perceived support from the university and the mesosystem. Socialization models emphasize that the setting of personal goals occurs in continuous interaction with the sociocultural context, which includes perceived opportunities to achieve these goals and the interpersonal environment. Both - perceived support from close people (mesosystems) and perceived support from the university - are significant for students. The study involved 432 university students between 18 and 49. We have assessed the extent to which students' goals regarding education, work, and personal growth are predicted by perceived opportunities to achieve these goals in Latvia and by the perceived support from parents, relatives, friends, classmates, teachers, and the university as an institution. The results of structural equation modeling revealed that personal growth goals are positively predicted by all three elements - the perceived opportunities to achieve these goals and the perceived academic and mesosystem support. The support of the classmates was connected to the support of the mesosystem that indicates the importance of friendly relations among students. Students' growth goals were the most closely associated with the perceived support in their specific environment - the university. In general, the results confirm the complex interaction of personal growth goals with the social and cultural environment in particular circumstances.
\end{abstract}

Keywords: academic support; growth goals; mesosystem support; perceived opportunities.

\section{Introduction}

People sometimes ask the question what their life would be if... Those considered "if 's" form different possible trajectories of individual's life how it would have been developed in one case or another. At the same time, asking such a question indicates that people are searching for fulfillment and meaning of their life. 
From a psychological perspective, the meaning of life is closely related to life goals as a group of highest priority goals for the individual (e.g., Emmons, 2003). Considering that life goals are made up of two main groups of goals relationships and growth goals (e.g., Seginer, 2009), - in so-called W.E.I.R.D. (western, educated, industrialized, rich, and democratic) societies, initially growth goals play a more important role for adolescents and emerging adults. It is because most individuals of these age groups, before starting their own family, study to become economically independent members of society and so to become able from the economic perspective to fully participate in family formation (Nurmi, 1991; Seginer, 2009). Thus, for both adolescents and emerging adults, current issues of life are closely related to the educational institutions on the one hand, to the closest relevant social group on the other, as well as to continuous interaction with a wider socio-economic context, where they see opportunities to fulfill their plans.

To explain these relationships, we will ground our study on a synthesis of three theoretical models: J.-E. Nurmi's (2004) Socialization and self-development model, J. J. Arnett's (2000) Emerging adulthood theory, and R. Seginer's (2009) Future orientation approach.

\section{Goals, Opportunities, and Support}

Nurmi (2004) points out that the environment is a factor that includes all possible life trajectories. The choice of a trajectory is largely determined by personal goals, perceived opportunities, and perceived support to achieve them. Perceived opportunities and perceived support, as opposed to real ones, are the main factors in the choice of specific development trajectories. Besides, culture largely determines characteristics of the environment, and perceived opportunities and perceived support are culture-specific (Gudykunst, 2004).

By summarizing theoretical models, Nurmi (2004) inferred that the development, socialization, and future orientation of adolescents and emerging adults is determined by the sociocultural environment on the one hand and interpersonal relationship environment on the other. The mechanism by which this development takes place involves four processes. The first process is channeling. Sociocultural and institutional predeterminants define the range of possibilities or possible trajectories of one's development and future. The second process is the selection, which is the selective use of offered alternatives. It is determined by motivation, interests, and personal goals. They lead individuals to specific educational pathways, certain interest groups, and certain recreational activities. The third process is the adjustment. Receiving feedback about their chosen developmental trajectories, adolescents adjust their goals, plans, and thinking, preserving, modifying, or changing these choices. The fourth process - 
the reflection - envisages the development of identity and self-conception, reflecting on current life and developmental issues. It takes place both by making conceptualizations about oneself and by communication with parents and peers.

Arnett (2000) points out that emerging adults' work experience is largely focused on the preparation for adult work roles and effective implementation of these roles. It leads to the conclusion that this age is crucial in the context of the individual`s future orientation since most individuals at this age choose opportunities they will stick to for the rest of their life. Therefore, such a perspective demands an understanding of underlying psychological mechanisms, especially in the interaction between channeling and selection. Research of this interaction can reveal the potential for successful adjustments or interventions in the life trajectories of emerging adults from both psychological and social perspectives. Simultaneously, it contains opportunities for individuals to understand and adjust their choices in a particular sociocultural environment and specific circumstances.

The second important aspect relates to the cultural factor. Arnett (2000) points out that emerging adulthood is currently very typical for industrial and postindustrial societies - Western cultures. Their specific requirements for the high level of education and training in information-based professions stimulate individuals to study longer and start families later. It determines the crucial role of education in industrial and postindustrial societies.

The qualitative analysis of the main goal formulations in Latvian adolescents and emerging adults (Kolesovs, Salima, \& Maskovs, 2018) also indicates that the main goal (or group of highest priority goals) forms the basis of the sense of life purpose and meaning; this is how the individual defines him-/herself. The most common categories in the formulation of this kind of goal are work, family, satisfaction, growth, fulfillment, the person himself, and education (Kolesovs, Salima, \& Maskovs, 2018). Thus, it confirms that the leading goals are related to the individual's growth, development, and close relationships.

Very important in the selection of future goals is the perceived support. Goal setting takes place in continuous interaction with interpersonal and institutional environments, including the learning environment (e.g., Machado, Brites, Magalhães, \& Sá, 2011). It is also confirmed in a study in Latvia (Kolesovs, 2019) that for students, growth-related goals consist of educational, occupational, and personal growth goals. They are the same goals that later in life, during adulthood, most commonly becomes the foundation of the meaning of one's life. These goals are positively predicted by the student's perceived support, which is formed by their views both about the academic staff and the university as a whole system.

Researchers from Israel and the Netherlands (Seginer, Vermulst, \& Shoyer, 2004) have investigated psychological mechanisms of future orientation, 
distinguishing three main components - motivation, cognitive representations, and future-related behavior. The motivational component consists of the value of the prospective life, expectations to succeed in the future, and internal control over the implementation of plans. The cognitive one consists of goals and plans regarding specific domains. The behavioral component consists of exploration (gathering information, seeking advice, evaluating their validity) and commitment or decisions on the choice of particular opportunities and devotion to them.

Parental support promotes the development of positive self-esteem, which further facilitates the above-mentioned components of future orientation, especially in educational and occupational domains (Seginer et al., 2004). The higher support for adolescents' autonomy relates to the higher goal-oriented motivation, which further directly facilitates cognitive representations and futurerelated behavior aimed at goal achievement.

\section{The Current Model}

It can be concluded that adolescents and emerging adults set their goals in surrounding cultural and social environments channeling them in possible trajectories. During the interaction between personal goals and context, an individual perceives opportunities for goal fulfillment and support from the closest people, the mesosystem (Bronfenbrenner, 1979), and the academic environment that can further facilitate goal achievement or selection of alternative opportunities.

Based on this conclusion, the authors propose a model that predicts students' growth-oriented goals with perceived opportunities and perceived support from both - the university and the mesosystem (Figure 1).

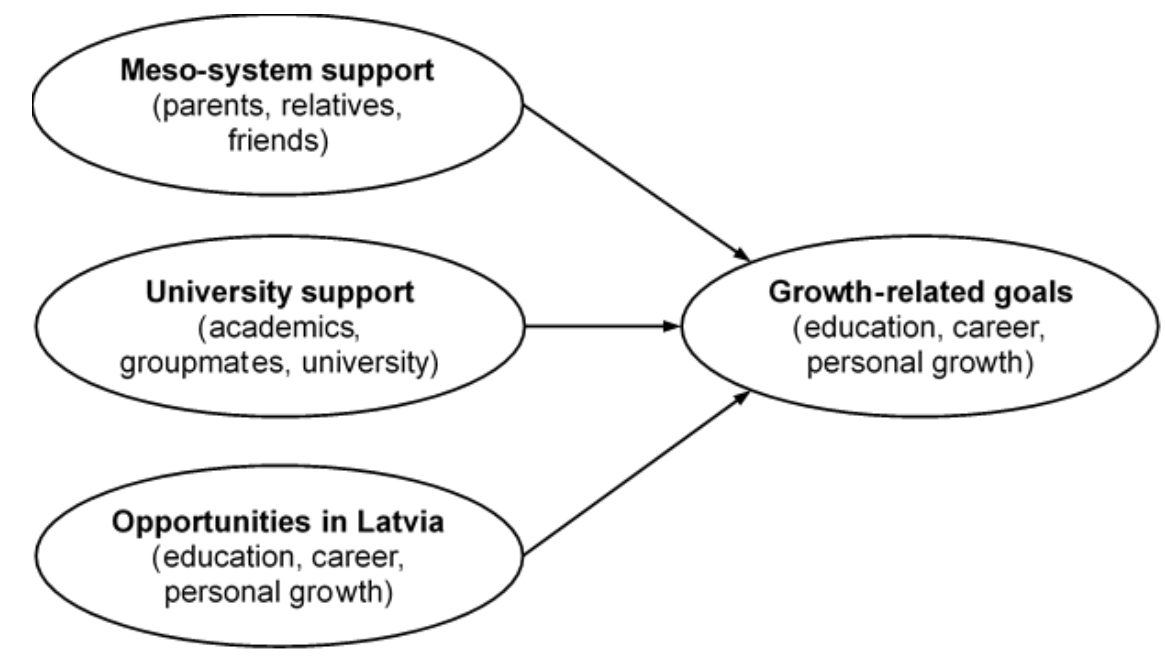

Figure 1 Conceptual Model of Prediction Students' Growth Goals (this study) 


\section{Method}

Participants. Participants were 432 university students 18 to $49(M=25.01$ years, $S D=6.73$ years, $73 \%$ were females). The convenience sample involved students from social sciences predominantly, and $61 \%$ of them were employed, $28 \%$ were graduated, $18 \%$ were married, and $10 \%$ had children.

Measures. The assessment of growth-oriented goals was based on items presenting distant goals in the domains of education, occupation, and personal growth (Kolesovs 2019). Participants used a seven-point scale (from 'not topical' to 'maximally') to answer the question: "To what extent your long-term goals are associated with the following domains [Cik lielā mērā Jūsu ilgtermiṇa mērḳi ir saistîti ar sekojošām jomām]?"

Perceived support at a mesosystem level was assessed by a measure suggested by Kolesovs (2015). It was assessed as support for goal attainment provided by parents, siblings, relatives, and friends. The assessment of educational support included three items presenting perceived support from groupmates, academic staff, and university in general. In this subscale, groupmates were added to the measure of educational support suggested by Kolesovs (2019).

To evaluate both kinds of social support, students answered the question: "To what extent your goals are supported by... [Cik lielā mērā Jūsu mērḳu sasniegšanu atbalsta...]?” They used a seven-point scale (from 'no support' to 'maximally')

Perceived opportunities for growth-oriented personal goals were assessed by answering the question: "To what extent do you perceive opportunities to fulfill your personal goals in Latvia in the given domains [Vai Latvijā redzat iespējas Jūsu mērḳu sasniegšanai norādītajās jomās]?" Three domains - education, occupation, and personal growth - were assessed on a seven-point scale (from 'minimally' to 'maximally').

Procedure. The study was conducted in 2019 and 2020. Participation in the study was voluntary and anonymous. The scale was administered in Latvian. Structural equation modelling (SEM) was performed by 'lavaan' (0.6-6) for R (Rosseel, 2012).

\section{Results}

The first step of SEM revealed slightly reduced fit of the model: $\chi^{2}(59)=$ $224.91, \mathrm{p}<.001, \mathrm{CFI}=.89, \mathrm{TLI}=.85$, RMSEA $=.081(90 \% \mathrm{CI}$ from .070 to $.091, \mathrm{p}<.001)$, SRMR $=.06$. 
A minimal modification of the model - adding factorial loading of the perceived support from groupmates on mesosystem support (Figure 2) - resulted in an acceptable fit of the model at the second step: $\chi^{2}(58)=162.04, \mathrm{p}<.001$, $\mathrm{CFI}=.93$, TLI $=.91$, RMSEA $=.064(90 \%$ CI from .054 to $.075, p=.015)$, SRMR $=.05$.

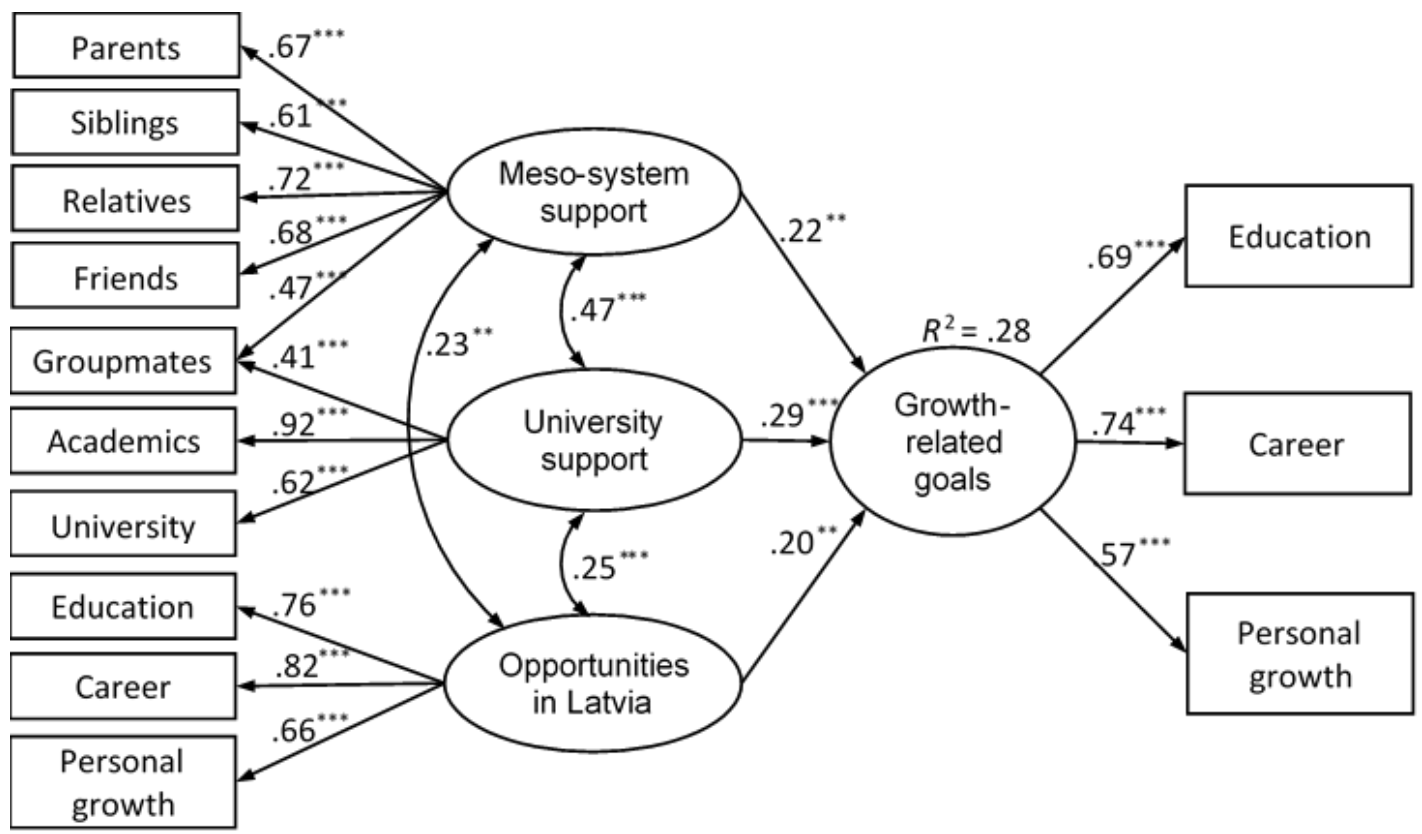

Figure 2 Predicting Students' Growth Goals by Perceived University and Mesosystem Support and Perceived Opportunities for Goal Achievement in Latvia

$$
\left({ }^{* *} p<.01,{ }^{* * *} p<.001\right)
$$

Simultaneously with acceptable fit, the improved model demonstrated metric invariance regarding students' gender, $\chi^{2}(10)=10.65, p=.385$, and employment, $\chi^{2}(10)=10.71, p=.381$.

\section{Discussion}

The authors tested the effect of channeling on personal goals (Nurmi, 2004) within a model considering students' growth-oriented goals as predicted by perceived opportunities and perceived support from both the university and the mesosystem.

Acquired results confirmed that perceived support from the mesosystem and university predicts students' growth goals positively. Perceived opportunities for the achievement of these goals in Latvia also predicted students' growth goals positively. Significant covariations indicated positive relationships among predictors. Among them, an association between both sources of support was closer than their associations with perceived opportunities. The level of explained 
variance of students' growth goals was not high (28\%). However, it confirmed a significant role of perceived support and opportunities in predicting these goals.

From a theoretical perspective, the results confirm that goal setting occurs in continuous person-context interaction. Perceived institutional support, interpersonal relationships, and perceived macro-contextual opportunities are elements of channeling (Nurmi, 2004), which provides the frame for selection and predicts growth-oriented goals.

The perceived specific support from the educational environment university support - is the most significant predictor of growth-oriented goals. This finding is in line with Arnett`s (2000) emerging adulthood theory, showing that education has a crucial role in forming possible life trajectories for students or, in most cases, emerging adults. Particularly, this kind of perceived support has the largest influence on selecting trajectories in the domain of education, career, and personal growth.

This study also confirms Seginer`s et al. (2004) future orientation approach and goes in line with studies done in Latvia (Kolesovs, 2015; 2019). First, Seginer's approach considers an opportunity to separate individual orientation to growth as an independent sphere of personal goals. In our study, it was supported by confirming the structure of latent variables. Second, our research shows environmental contribution facilitating personal goals - this goes along with Seginer's (2009) theory of future orientation.

\section{Limitations and Further Directions}

It should be noted that our study has several limitations. Participants were motivated to involve in the study. Therefore, the level of involvement in the study can interfere with the level of goals and university support. It is useful to replicate these results involving an alternative model of interaction, for example, asking other students to be data collectors.

Some sources of perceived support (e.g., romantic partner) were not included in the analysis, therefore it would be added value in future research, understanding their influence within the proposed model of goal-context interaction. Similarly, the prediction of other kinds of goals (e.g., relational or pragmatic) can be assessed in the future.

Regarding ecological validity, one of the contextual implications for this study is concerned with the Covid-19 pandemic. The research was done during changes in studying format because of the pandemic, so there is a possibility that reducing physical social interaction with groupmates and academic staff could influence perceived support from both the university and the mesosystem. 
Freibergs \& Kolesovs, 2021. University Students’ Growth Goals, Opportunities for Goal Fulfillment, and Perceived University and Mesosystem Support

For a generalization outside the Latvian sociocultural context, a crosscultural study will be helpful. Moreover, there is a necessity to replicate results not only in the so-called W.E.I.R.D. societies, but in other sociocultural models. It will give a broadened perspective on aspects like - does it always work for adolescents and emerging adults; are there other educational models or none of them; are the results similar for individualistic and collectivistic cultures, or do they have distinct patterns.

\section{Conclusions}

To sum up, the results confirm the complex interaction of personal growth goals with the social and cultural environment. Focusing on two sources of support - mesosystem and university - revealed their mutual relationships and predictive potential for the individual pursuit for personal growth in a specific sociocultural context. Opportunities for achieving personal goals in Latvia are also a positive predictor for orientation to these goals. However, the most significant predictor was perceived support from the university - as a context for students' development and growth.

\section{Acknowledgements}

The study was performed within the project "Perceived academic support in the prediction of students' sense of belonging to Latvia and emigration intentions" supported by the University of Latvia (No. Y5-AZ22-ZF-N-040). The authors would like to thank students who voluntarily participated in the study.

\section{References}

Arnett, J. J. (2000). Emerging adulthood: A theory of development from the late teens through the twenties. American Psychologist, 55(5), 469-480. https://doi.org/10.1037/0003066X.55.5.469

Emmons, R. A. (2003). Personal goals, life meaning, and virtue: Wellsprings of a positive life. In C. L. M. Keyes \& J. Haidt (Eds.), Flourishing: Positive psychology and the life welllived (pp. 105-128). American Psychological Association. https://doi.org/10.1037/ 10594-005

Gudykunst, W. B. (2004). Understanding cultural differences. In Bridging differences: Effective intergroup communication (pp. 41-73). Thousand Oaks, CA: SAGE Publications, Inc. http://dx.doi.org/10.4135/9781452229706.n2

Kolesovs, A. (2015). Prediction of distant educational goals by goals in other domains and perceived contextual opportunities. In V. Lubkina, \& S. Usca (Eds.), Society, Integration, Education: Vol. 4. Proceedings of the International Scientific Conference (pp. 40-47). Rēzekne: Rēzeknes Augstskola. https://doi.org/10.17770/sie2015vol4.335 
Kolesovs, A. (2017). Individual future orientation and demographic factors predicting life satisfaction. In V. Lubkina, I. Baranauskiene, \& K. Mārtinsone (Eds.), Society, Integration, Education: Vol. 1, Proceedings of the International Scientific Conference (pp. 534-543). Rezekne: Rezekne Academy of Technologies. https://doi.org/ 10.17770/sie2017vol1.2448

Kolesovs, A. (2019). The ethnolinguistic group, gender, and perceived educational support as predictors of growth-oriented goals in university students from Latvia. Proceedings of the 13th International Technology, Education and Development Conference (pp. 13611364). https://doi.org/10.21125/inted.2019.0427

Kolesovs, A., Salima, I., \& Maskovs, A. (2018). Formulations of the main goal in life: A qualitative content analysis. In V. Lubkina, K. Šneidere, S. Ušča, \& A. Zvaigzne (Eds.), Society, Integration, Education: Vol. VII. Proceedings of the International Scientific Conference (pp. 104-114). Rezekne: Rezekne Academy of Technologies. https://doi.org/10.17770/sie2018vol1.3108

Machado, M.D.L., Brites, R., Magalhães, A., \& Sá, M. (2011). Student satisfaction with higher education: Critical data for student development. European Journal of Education, 46(3), 415-432. Retrieved from https://www.researchgate.net/deref/http\%3A\%2F\%2Fdx. doi.org\%2F10.1111\%2Fj.1465-3435.2011.01489.x

Nurmi, J.-E. (2004). Socialization and self-development: Channeling, selection, adjustment, and reflection. In R. M. Lerner \& L. Steinberg (Eds.), Handbook of adolescent psychology (pp. 85-124). John Wiley \& Sons Inc. https://doi.org/10.1002/9780471726746.ch4

Rosseel, Y. (2012). lavaan: An R package for structural equation modeling. Journal of Statistical Software, 48(2), 1-36. https://doi.org/10.18637/jss.v048.i02

Seginer, R., Vermulst, A., \& Shoyer, S. (2004). The indirect link between perceived parenting and adolescent future orientation: A multiple-step model. International Journal of Behavioral Development, 28(4), 365-378. https://doi.org/10.1080/01650250444000081

Seginer, R. (2009). Future orientation: Developmental and ecological perspectives. New York, NY: Springer. https://doi.org/10.1007/b106810 